\title{
Comparison of the spatial patterns of schistosomiasis in Zimbabwe at two points in time, spaced twenty-nine years apart: is climate variability of importance?
}

\author{
Ulrik B. Pedersen, ${ }^{1}$ Dimitrios-Alexios Karagiannis-Voules, ${ }^{2}$ Nicholas Midzi, ${ }^{3}$ \\ Tkafira Mduluza, ${ }^{4}$ Samson Mukaratirwa, ${ }^{5}$ Rasmus Fensholt, ${ }^{6}$ Birgitte J. Vennervald, ${ }^{1}$ Thomas \\ K. Kristensen, ${ }^{1,5}$ Penelope Vounatsou, ${ }^{2}$ Anna-Sofie Stensgaard ${ }^{7}$ \\ ${ }^{1}$ Department of Disease Biology, Faculty of Health Sciences and Medical Sciences, University of \\ Copenhagen, Frederiksberg, Denmark; ${ }^{2}$ Department of Public Health and Epidemiology, Swiss Tropical \\ and Public Health Institute, University of Basel, Basel, Switzerland; ${ }^{3}$ Department of Biochemistry, \\ University of Zimbabwe, Harare; ${ }^{4}$ Department of Medical Microbiology, College of Health Sciences, \\ University of Zimbabwe, Harare, Zimbabwe; ${ }^{5}$ School of Life Sciences, University of KwaZulu-Natal, \\ Westville, South Africa; ${ }^{6}$ Department of Geosciences and Natural Resource Management, University of \\ Copenhagen, Copenhagen; ${ }^{7}$ Center for Macroecology, Evolution and Climate, Natural History Museum of \\ Denmark, University of Copenhagen, Copenhagen, Denmark
}

\begin{abstract}
Temperature, precipitation and humidity are known to be important factors for the development of schistosome parasites as well as their intermediate snail hosts. Climate therefore plays an important role in determining the geographical distribution of schistosomiasis and it is expected that climate change will alter
\end{abstract}

Correspondence: Ulrik Bo Pedersen, Department of Disease Biology, Faculty of Health Sciences and Medical Sciences, University of Copenhagen, Snedronningvej 25, DK-2730 Herlev, Denmark.

Tel: +45.3122 .3866$

E-mail: ubpedersen@hotmail.com

Acknowledgments: ASS thanks the Danish National Research Foundation for support to the Center for Macroecology, Evolution and Climate (DNRF96)

Note: UBP and D-A K.V share first authorship.

Conflict of interest: the authors declare no potential conflict of interest.

Clinical trials: Medical Research Council of Zimbabwe, ethical approval number MRCZ/A/1207 dated $11^{\text {th }}$ March 2010.

Key words: Schistosomiasis; Climate change; Zimbabwe; Geospatial prediction.

Received for publication: 1 September 2016

Revision received: 14 December 2016.

Accepted for publication: 22 December 2016.

(C) Copyright U.B. Pedersen et al., 2017

Licensee PAGEPress, Italy

Geospatial Health 2017; 12:505

doi:10.4081/gh.2017.505

This article is distributed under the terms of the Creative Commons Attribution Noncommercial License (CC BY-NC 4.0) which permits any noncommercial use, distribution, and reproduction in any medium, provided the original author(s) and source are credited. distribution and transmission patterns. Reliable predictions of distribution changes and likely transmission scenarios are key to efficient schistosomiasis intervention-planning. However, it is often difficult to assess the direction and magnitude of the impact on schistosomiasis induced by climate change, as well as the temporal transferability and predictive accuracy of the models, as prevalence data is often only available from one point in time. We evaluated potential climate-induced changes on the geographical distribution of schistosomiasis in Zimbabwe using prevalence data from two points in time, 29 years apart; to our knowledge, this is the first study investigating this over such a long time period. We applied historical weather data and matched prevalence data of two schistosome species (Schistosoma haematobium and S. mansoni). For each time period studied, a Bayesian geostatistical model was fitted to a range of climatic, environmental and other potential risk factors to identify significant predictors that could help us to obtain spatially explicit schistosomiasis risk estimates for Zimbabwe. The observed general downward trend in schistosomiasis prevalence for Zimbabwe from 1981 and the period preceding a survey and control campaign in 2010 parallels a shift towards a drier and warmer climate. However, a statistically significant relationship between climate change and the change in prevalence could not be established.

\section{Introduction}

Schistosomiasis is a human disease caused by parasitic trematodes that have a freshwater snail as intermediate host. Of the five known species adapted to humans, Schistosoma haematobium, $S$. mansoni and $S$ japonicum are the most common species, while $S$. mekongi and $S$. intercalatum are limited to minor areas, the first in Asia and the second in Africa. Schistosoma haematobium and S. mansoni are found in large parts of the African continent, the former causing urinary schistosomiasis with Bulinus globosus as intermediate host and the latter intestinal schistosomiasis with Biomphalaria pfeifferi as intermediate host. Overall, an estimated 207 million people are infected and 779 million live in areas where transmission is on-going (Chitsulo et al., 2000; Fürst et al., 
2012; Stensgaard et al., 2013, 2016). Schistosomiasis is present in the eleven provinces of Zimbabwe and mainly predominant in the North, Northeast and Central highlands, with the prevalence ranging from 3.3 to $39.3 \%$ amongst $10-15$ year olds according to the most recent survey (Midzi et al., 2014).

Climate variables, such as temperature and precipitation have been shown to drive schistosomiasis distribution (Malone et al., 2001; Moodley et al., 2003; Stensgaard et al., 2006, 2013; Schur et al., 2011, 2013) and used for the prediction of infection risk at locations where schistosomiasis prevalence has not been surveyed. These predictions can be displayed as smoothed risk maps and serve as a decision support tool for health planning and control (Raso et al., 2005; Simoonga et al., 2009; Woodhall et al., 2013; Assare et al., 2015). However, due to the central role of climate, the spatial distribution of schistosomiasis might change in the future with anticipated climate change (McCreesh and Booth, 2013). Reliable projections of future distributions and risk are thus needed for timely and efficient schistosomiasis intervention planning. A number of studies have used climate projection data in an attempt to produce such future transmission scenarios (Martens et al., 1997; Moodley et al., 2003; Yang et al., 2005; Zhou et al., 2008; Stensgaard et al., 2013, 2016; McCreesh et al., 2015). However, the effect of climatic change has never been investigated using historical climate data, which could otherwise help to validate the direction and magnitude of changes in prevalence.

Here, we use $S$. mansoni and $S$. haematobium prevalence data from two national surveys conducted in Zimbabwe in 1981 and 2010 , as well as climate data covering the same two periods. The objective was to describe the spatial distributional changes of urogenital and intestinal schistosomiasis prevalence in Zimbabwe between these two points in time and to explore whether any observed changes can be attributed to changes in environmental or other risk factors over this time period.

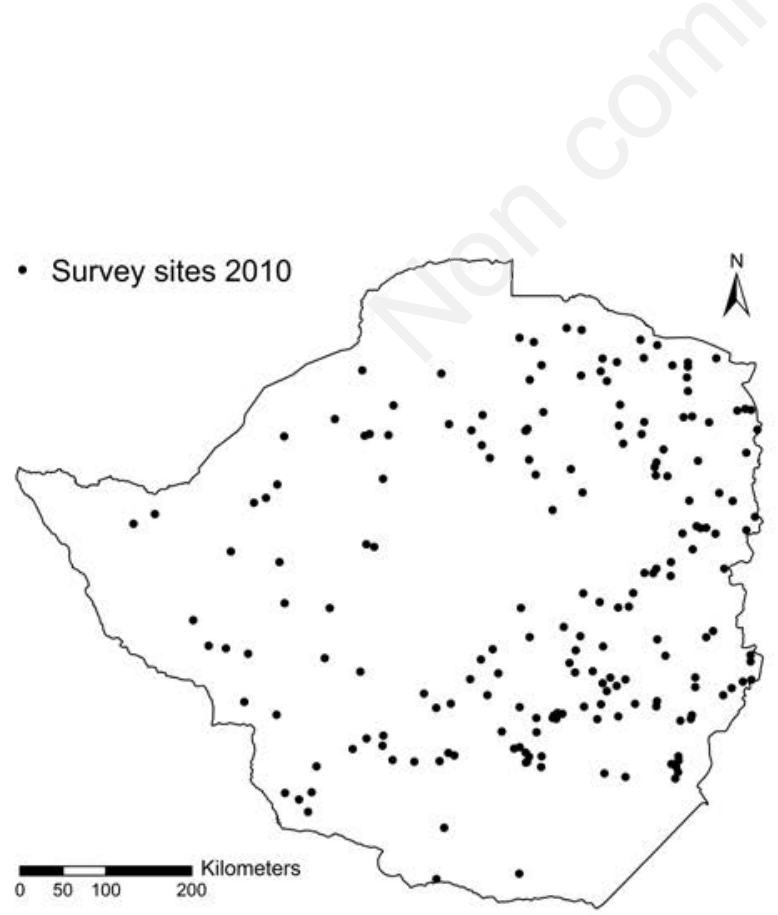

\section{Materials and Methods}

\section{Schistosomiasis survey data}

Two datasets on prevalence of S. mansoni and S. haematobium in school-aged children were provided by the Zimbabwe National Institute of Health Research (former Blair Research Laboratories) (Figure 1). The first survey was carried out in 1981 (Taylor and Makura, 1985) where urine and stool samples were collected from 14,619 school-going children aged eight to ten years from 166 different schools. The observed average prevalence of $S$. haematobi$u m$ and $S$. mansoni was $41 \%$ (range: $0-97 \%$ ), and $8 \%$ (range: 0 $81 \%$ ), respectively. The second survey was conducted in 2010 (Midzi et al., 2011) where urine and stool samples were obtained from 13,187 school-going children aged 10 to 15 years in 330 rural and urban schools with an over-all prevalence of $22.7 \%$. The $S$. haematobium prevalence was $18 \%(0-76 \%)$ and that of $S$. mansoni $7.2 \%(0-64 \%)$.

Children were enrolled randomly in both surveys and all rural districts in the country were represented. Schools were semi-randomly selected allowing adjustment for district representation and samples of urine and faeces were obtained from 50 children at each school. Egg counts from urine samples were determined through sedimentation followed by microscopy and by Kato-Katz from faeces following the method as described by Katz et al. (1972). An additional formol-ether concentration of faecal samples and urine filtration technique for urine samples was added in the 2010-survey to improve sensitivity (Cheesbrough, 2006).

The two comparative surveys were conducted 29 years apart focussing on contemporary baseline information on schistosomiasis prevalence and on health intervention purposes; hence, attention was not specifically paid to homogeneity between the studied age groups.

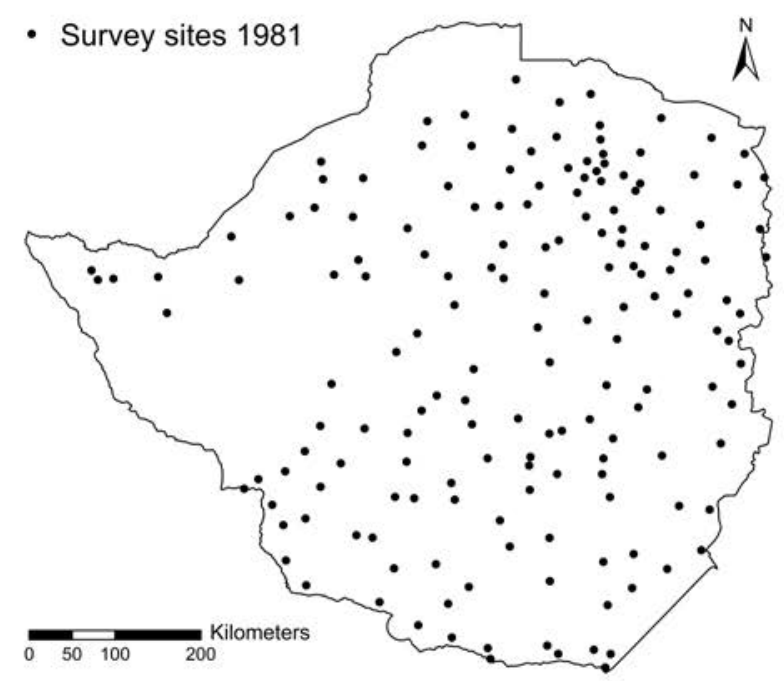

Figure 1. Locations of the schools surveyed for urogenital and intestinal schistosomiasis 29 years apart. 


\section{Environmental data}

Data on climate, environment, and risk factors (Table 1) were taken from publicly available databases or provided directly by the data-holder and all climate variables were implemented in the model as averages of March to May. This period is of importance because of the rapid development of the intermediate host snail populations following the rainy season that takes place from December to February (Mukaratirwa and Kristensen, 1995) in Zimbabwe. Climate variables used for fitting of the model were rainfall, temperature and the climate proxy for moisture availability, the normalised difference vegetation index (NDVI). The rainfall data were modelled from rain-gauge measurements and remotely sensed data from satellite-borne instruments (Novella and Thiaw, 2012). For NDVI, the average for 1982, 1983 and 1984 (Tucker et al., 2005; Pinzon and Tucker, 2014) was used as a substitute for 1981 because no data are available for March, April and May of that year. Temperature data were from the WorldClim dataset (Hijmans et al., 2005), which is a long-term average (19502000) as no year-specific temperature data is available for 1981. Other predictor variables included elevation (Jarvis et al., 2008), soil pH and total available water capacity (TAWC) (Batjes, 2012) and the Human Footprint dataset (Wildlife Conservation Society and Center for International Earth Science Information Network, 2005). In order to express the risk for schistosome infection, data on population density 2010 (Tatem et al., 2007) and 1990 (Center for International Earth Science Information Network et al., 2011) as well as on rivers (Lehner et al., 2006) were utilised together with the Human Transmission Index (HTI) being a product of distance to nearest river from a given grid cell and the population density in the grid cell. All environmental parameters were re-sampled to a 10 by 10 arc degree grid with a resolution of 0.1 arc degree ( $\sim 10 \mathrm{~km}$ ) using ArcMap v. 10.2 (ESRI, Redlands, CA, USA).

\section{Model implementation}

A total of four Bayesian geostatistical logistic regression models were fitted to the $S$. haematobium and $S$. mansoni prevalence data from each time period (i.e. 1981 and 2010). Spatial correlation was modelled via a normally distributed spatial random effect with exponential correlation function. A Bayesian stochastic search variable selection (Edward and McCulloch, 1993; Dellaportas et al., 2000) was carried out to identify the combination of the most important predictors and their functional form. The forms considered were continuous and categorical with three and four categories based on each variable's quintiles. Classified sets of highly correlated covariates (Pearson's correlation coefficient $>0.9$ ) were selected among and only one of the variables was selected to avoid collinearity. The set of covariates with the highest posterior probability was selected to fit the final Bayesian geostatistical model following the approach of Chammartin et al. (2013). Bayesian Kriging was applied, using the final model, to predict the risk of schistosomiasis at the 0.1 arc degree resolution $(\approx 10 \times 10 \mathrm{~km})$ in a grid of 10,000 pixels covering Zimbabwe and parts of neighbouring countries.

Analyses were implemented in WinBUGS (Lunn et al., 2000) and R (R Core Team, 2013). Predictions were programmed in Visual Fortran version 6.0 (Digital Equipment Corporation, Maynard, MA, USA). Mapping was performed in ArcMap 10.2 (ESRI).

\section{Results}

\section{Spatial statistical modelling and variable selections}

The most important predictors identified in each of the four models (two forms of schistosomiasis at two points in time), following the Bayesian variable selection procedure are presented in Table 2. The higher category of the HTI was found to significantly affect the spatial distribution of $S$. haematobium in 1981 with a positive association. In 2010 on the other hand, a higher risk of $S$. haematobium infection was significantly associated with lower soil $\mathrm{pH}$ values, while the $S$. mansoni distribution was negatively associated with high levels of human disturbance (human footprint) and the lower category of HTI in 1981, whereas a positive association with high water availability (TAWS) was found. Low levels of HTI, high TAWS and altitude were all negatively associated with $S$. mansoni infection in 2010.

Temperature and precipitation were not selected as important predictors in any of the four Bayesian geostatistical models following the variable selection procedure. NDVI was selected for inclusion in the 1981 urogenital schistosomiasis model, however it did not explain disease distribution at a significant level.

\section{Predictive risk maps of Schistosoma mansoni and Schistosoma haematobium infection in 1981 and 2010}

The predicted prevalence's are mapped in Figure 2 with red colours indicating higher predicted prevalence. It is apparent that the extent of areas with high-predicted prevalence was reduced in 2010 compared to 1981 for $S$. haematobium and that S. mansoni prevalence was reduced in some parts, while it increased in other parts of the country.

Schistosoma haematobium infection occurred with high prevalence in most areas in 1981 (Figure 2A), whereas, in 2010, hotspots were concentrated in the North-east and in a southern section, but with infections still found in all parts of Zimbabwe (Figure 2B). The predicted $S$. mansoni infection risk was generally lower than that of $S$. haematobium in both years (Figure $2 \mathrm{C}$ and 2D), but with high-predicted prevalence in the same northern

Table 1. Specifics of data used for prevalence prediction

\begin{tabular}{|c|c|c|c|}
\hline Dataset & \multicolumn{2}{|c|}{ Source } & $\begin{array}{l}\text { Resolution } \\
\text { (km) }\end{array}$ \\
\hline Rainfall* & ARC2 & $\mathrm{ARC2}$ & 10 \\
\hline $\mathrm{NDVI}^{\circ}$ & GIMMS3-g & GIMMS3-g & 8 \\
\hline Population density & GRUMP, vl (1990) & Afripop (2010) & $\sim 1$ \\
\hline Rivers $^{\S}$ & \multicolumn{2}{|c|}{ HydroSHED } & $\sim 0.5$ \\
\hline 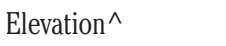 & \multicolumn{2}{|c|}{ SRTM Digital Elevation Database } & $\sim 0.1$ \\
\hline Human footprint $\$$ & \multicolumn{2}{|c|}{ Global Human Footprint } & $\sim 1$ \\
\hline Soil pH** & \multicolumn{2}{|c|}{ ISRIC-WISE } & 10 \\
\hline TAWS** & \multicolumn{2}{|c|}{ ISRIC-WISE } & 10 \\
\hline Temperature $^{\circ \circ}$ & \multicolumn{2}{|c|}{ WorldClim } & $\sim 1$ \\
\hline \multicolumn{4}{|c|}{$\begin{array}{l}\text { NDVI, normalised difference vegetation index; TAWS, high water availability. *ftp.cpc.ncep.noaa.gov/fews; } \\
{ }^{\circ} \text { www.nasa.gov/centers/goddard; \#http://sedac.ciesin.columbia.edu/data/set/grump-vl-population-densi- } \\
\text { ty/data-download (1990), http://worldmap.harvard.edu/data/geonode:AfriPoplkm_QCe (2010); } \\
\text { \$http://hydrosheds.org/; ^ } \text { www.cgiar-csi.org/data; \$http://sedac.ciesin.columbia.edu/data/set/wildareas- } \\
\text { v2-human-footprint-geographic; ***www.isric.org; }{ }^{\circ} \text { http://www.worldclim.org/current. }\end{array}$} \\
\hline
\end{tabular}


hotspot areas as $S$. haematobium in 2010. A predicted high S. mansoni prevalence area in the South in 2010 was positioned further to the Southeast than the hotspot of S. haematobium. Comparison of the prediction maps for $S$. mansoni, revealed that there had been a geographical shift in high-risk areas from the western to the eastern part of the country during the 29 -year study period.

\section{Predicted changes in schistosomiasis from 1981 to 2010}

To follow the development from 1981 to 2010, the predicted prevalence maps were subtracted pixel-by-pixel to produce maps of change in absolute prevalence values (Figure 3). The change of urogenital schistosomiasis depicted in Figure 3A, ranges from an 80 percentage-point decrease to a 53 percentage-point increase. Large areas of substantial decrease are present in the Northwestern part of Zimbabwe (blue colour). Large areas experienced unchanged prevalence ( $+/-20$ percentage points) (yellow/orange), while some saw an up to 53 percentage-points increase (light red). The reduction of the predicted distribution of $S$. mansoni was most pronounced in the Northeast, where an up to 84 percentage-point decrease was observed (Figure 3B). Parts of the highveld and southern Zimbabwe experienced a low-level decrease, while there were zones with increases reaching 65 percentage-points in some clusters (dark orange).

\section{Estimates of the number people infected}

The total number of people infected was derived from the predicted prevalence and two datasets on population density, i.e. 1990 and 2010 (Tatem et al., 2007; Center for International Earth Science Information Network et al., 2011) (Table 1). The number of people estimated to have been infected with $S$. haematobium in 2010 was 2,129,309 (population adjusted prevalence of $17.3 \%$ ), i.e. a strong reduction from $4,382,835$ (population adjusted prevalence of $41.5 \%$ ) in 1981 , while the number of $S$. mansoni infections was reduced to $622,549(5.1 \%)$ in 2010 from $992,249(9.4 \%)$ in 1981 .

\section{Discussion}

Our results show that the prevalence of $S$. haematobium and $S$. mansoni declined in Zimbabwe over the past three decades, while the spatial patterns remained unchanged with hotspots at the same locations, albeit at lower levels. These findings are in line with the findings of Lai and colleagues (Lai et al., 2015) who demonstrated a general, declining trend in $S$. mansoni and $S$. haematobium in sub-Saharan Africa (SSA) from 2000 onwards. They are also partly in line with Schur and colleagues (2013), whose study in East

Table 2. Explanatory variables of Schistosoma haematobium and Schistosoma mansoni in 1981 and 2010 as selected by the Bayesian variable selection procedure.

\begin{tabular}{|c|c|c|c|c|c|c|c|}
\hline Variables & Schis & $\begin{array}{l}\text { tosoma } \\
\text { BCI } \\
\text { OR 1981 }\end{array}$ & matobium & Variables & Sch & $\begin{array}{l}\text { osoma } n \\
\text { BCI } \\
\text { OR } 198\end{array}$ & \\
\hline & Median & Lower & Upper & & Median & Lower & Upper \\
\hline HTI & & & & HTI & & & \\
\hline $\begin{array}{l}0.00625-0.01587 \\
>0.01587 \\
\text { Human footprint }\end{array}$ & $\begin{array}{l}1.14 \\
0.53 \\
0.98\end{array}$ & $\begin{array}{l}0.73 \\
0.33 \\
0.95\end{array}$ & $\begin{array}{l}1.78 \\
0.86 \\
1.00\end{array}$ & $\begin{array}{l}0.00625-0.01587 \\
>0.01587 \\
\text { Human footprint } \\
29-34 \\
>34\end{array}$ & $\begin{array}{l}0.46 \\
0.78 \\
\\
0.84 \\
0.54\end{array}$ & $\begin{array}{l}0.26 \\
0.43 \\
0.40 \\
0.31\end{array}$ & $\begin{array}{l}0.80 \\
1.42 \\
\\
1.79 \\
0.95\end{array}$ \\
\hline NDVI & & & & TAWC & & & \\
\hline $\begin{array}{l}0.51-0.58 \\
>0.58 \\
\text { Variance } \\
\text { Spatial range* }(\mathrm{km})\end{array}$ & $\begin{array}{c}1.66 \\
1.78 \\
2.41 \\
72.72\end{array}$ & $\begin{array}{c}0.94 \\
0.93 \\
1.74 \\
53.12\end{array}$ & $\begin{array}{c}2.96 \\
3.40 \\
3.34 \\
97.62\end{array}$ & $\begin{array}{l}\text { 8-11.8 } \\
>11.8 \\
\text { Variance } \\
\text { Spatial range* }(\mathrm{km})\end{array}$ & $\begin{array}{c}0.94 \\
2.65 \\
4.31 \\
103.7\end{array}$ & $\begin{array}{c}0.45 \\
1.25 \\
2.84 \\
76.02\end{array}$ & $\begin{array}{c}1.95 \\
5.61 \\
6.70 \\
141.7\end{array}$ \\
\hline & & OR 2010 & & & & OR 2011 & \\
\hline $\begin{array}{l}\text { Altitude (m) } \\
888-1136 \\
>1136\end{array}$ & $\begin{array}{l}0.59 \\
0.48\end{array}$ & $\begin{array}{l}0.32 \\
0.22\end{array}$ & $\begin{array}{l}1.11 \\
1.03\end{array}$ & $\begin{array}{l}\text { Altitude (m) } \\
888-1136 \\
>1136\end{array}$ & $\begin{array}{l}0.22 \\
0.18\end{array}$ & $\begin{array}{l}0.08 \\
0.05\end{array}$ & $\begin{array}{l}0.63 \\
0.58\end{array}$ \\
\hline Soil pH & & & & HTI & & & \\
\hline $6.21-6.27$ & 0.18 & 0.05 & 0.60 & $\begin{array}{l}<0.01473 \\
0.00625-0.01473\end{array}$ & $\begin{array}{l}0.40 \\
0.54\end{array}$ & $\begin{array}{l}0.19 \\
0.25\end{array}$ & $\begin{array}{l}0.84 \\
1.13\end{array}$ \\
\hline & & & & TAWC & & & \\
\hline$<6.27$ & 0.21 & 0.11 & 0.41 & $\begin{array}{l}8-8.23 \\
8.23-11.6 \\
>11.6\end{array}$ & $\begin{array}{l}2.2 \\
0.19 \\
0.11\end{array}$ & $\begin{array}{l}0.35 \\
0.06 \\
0.03\end{array}$ & $\begin{array}{l}12.7 \\
0.54 \\
0.35\end{array}$ \\
\hline $\begin{array}{l}\text { Variance } \\
\text { Spatial range* }(\mathrm{km})\end{array}$ & $\begin{array}{l}2.61 \\
44.6\end{array}$ & $\begin{array}{l}1.83 \\
29.9\end{array}$ & $\begin{array}{l}3.74 \\
64.5\end{array}$ & $\begin{array}{l}\text { Variance } \\
\text { Spatial range* }(\mathrm{km})\end{array}$ & $\begin{array}{l}5.61 \\
46.3\end{array}$ & $\begin{array}{l}3.56 \\
28.5\end{array}$ & $\begin{array}{l}8.78 \\
69.8 \\
\end{array}$ \\
\hline
\end{tabular}

OR, odds ratio; BCI, Bayesian credible interval (95\%); HTI, human transmission index; NDVI, normalised difference vegetation index; TAWC, total available water capacity.*Minimum distance (spatial correlation remains important at the $\mathrm{km}$ level). Significant associations are in italics. 
Africa showed a lower infection risk for S. haematobium in the past two decades, and a lower infection risk for S. mansoni since 2000. The trend in historical data on schistosomiasis and climate for Zimbabwe presented in this paper, corroborates these findings and indicates that the response from schistosomiasis to climatic changes is an on-going phenomenon. The Bayesian geostatistical models with the highest posterior probabilities did still not select any of the climatic covariates except for NDVI, which was not significant. The HTI, soil $\mathrm{pH}$, TAWS and altitude, on the other hand, were selected as either positively or negatively associated with schistosomiasis risk. This means that human activities, soil characteristics and altitude are more important drivers than the climate data in the implemented modelling framework. Therefore we cannot conclude that observed changes in schistosomiasis over the three decades is attributable to the observed changes in climatic conditions (drying and warming) in Zimbabwe. Local scale factors such as health education, migration, etc. is also known to influence risk patterns, yet such data were not available at the national level, nor at the specific time points investigated. This, notwithstanding, our results are in line with other, recent studies that have shown that a reduction in the geographical distribution of the schistosome intermediate host snails is linked to changes in temperature, precipitation and humidity (Stensgaard et al., 2013, 2016; Pedersen et al., 2014a, 2014b). These studies found that currently climatically suitable areas in many places in Africa will either become too hot or too dry under future climate change scenarios to sustain many of the intermediate host snail species.

A number of issues concerning both the survey data and the environmental variables used to parameterize the geostatistical models might have had an impact on the results and therefore could potentially influence the conclusions drawn. First and foremost, different age groups were tested in the two national surveys and as prevalence is known to vary amongst age groups (see review in (Guyatt et al., 1999), this could have introduced a systematic error. In 1981, 8-10 year old school-aged children were tested, whereas in 2010, the age group was 10-15 year olds. Several studies show that prevalence peaks towards 15-20 years of age (Hairston, 1965; Taylor and Makura, 1985; Chandiwana et al., 1988; El-Khoby et al., 2000; Kabatereine et al., 2004) but the peak may occur earlier in high-prevalence areas (Traoré et al., 1998). The prevalence in both years is relatively high in the highprevalence areas compared to other study areas (Lwambo et al., 1999; Kabatereine et al., 2004; Clements et al., 2006; Raso et al., 2007; Schur et al., 2011) thereby justifying a direct comparison of the two surveys. The age group in 2010 is in fact closer to the peak prevalence age class and the reduction observed from 1981 to 2010 would, in theory, had been more pronounced should the age groups tested have been the same, thereby providing support for the observed reduced prevalence.

Secondly, it could be argued that the observed reduction of

\section{Predicted prevalence}

\begin{tabular}{|l|l|}
\hline & $0.95-1.00$ \\
\hline & $0.90-0.95$ \\
\hline & $0.85-0.90$ \\
& $0.80-0.85$ \\
& $0.75-0.80$ \\
\hline & $0.70-0.75$ \\
\hline & $0.65-0.70$ \\
\hline & $0.60-0.65$ \\
\hline & $0.55-0.60$ \\
\hline & $0.50-0.55$ \\
\hline & $0.45-0.50$ \\
\hline & $0.40-0.45$ \\
\hline$\square$ & $0.35-0.40$ \\
\hline$\square$ & $0.30-0.35$ \\
\hline$\square$ & $0.25-0.30$ \\
\hline$\square$ & $0.20-0.25$ \\
\hline$\square$ & $0.15-0.20$ \\
\hline$\square$ & $0.10-0.15$ \\
\hline$\square$ & $0.05-0.10$ \\
\hline$\square$ & $0.00-0.05$ \\
\hline
\end{tabular}

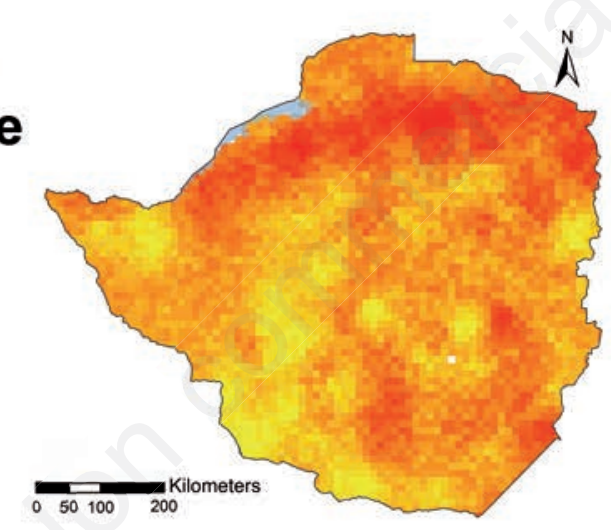

A

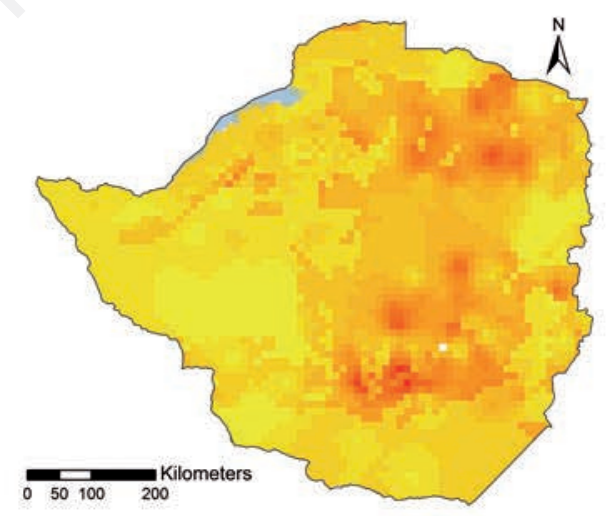

B
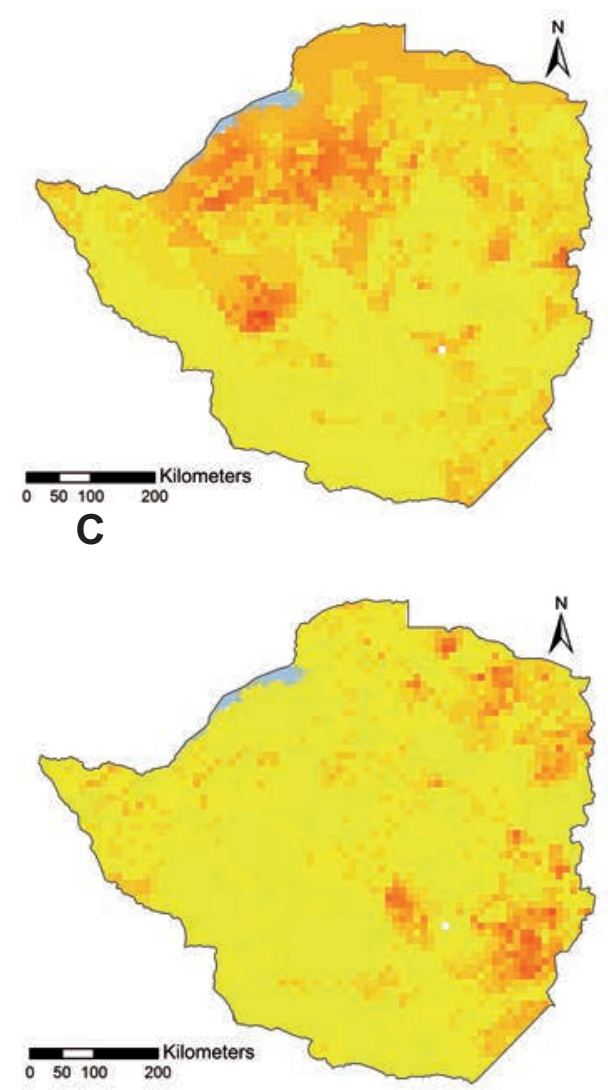

D

Figure 2. Median predicted prevalence of urogenital and intestinal schistosomiasis for 1981 and 2010. Urogenital and intestinal schistosomiasis for 1981 (A and C) and 2010 (B and D). High-intensity red colour indicates high prevalence. 
both forms of schistosomiasis might be attributed to mass drug administration campaigns (MDAs) and to changes in (risk) behaviour. However, according to national health authorities (Midzi et al., 2011), no interventions at the national scale has been carried out in the interim period. Local MDAs may, however, have occurred, but these would only have affected this comparative study if carried out in the immediate years leading up to the surveys as prevalence is known to return to pre-MDA levels within few years (Clements et al., 2009).

Risk behaviour, inadequate toilets facilities, swimming and domestic use of unsafe water sources, may have changed and contributed to the observed prevalence reduction. We did not investigate these factors quantitatively because no historical data are available three decades back, though reports obtained during the 2010 survey (Midzi et al., 2011) indicates that the environment where many of the schoolchildren in the rural districts live, still is characterized by unsafe water, poor lavatory facilities and low awareness/compliance with best practises.

The total number of infections in Zimbabwe is calculated as a simple product of predicted prevalence among schoolchildren and population density. We did not use specifically age-adjusted population estimates as these were not available historically. Since the prevalence is known to peak among school-aged children (Fulford et al., 1998; Guyatt et al., 1999; Kabatereine et al., 2004), the presented results are likely to be overestimated, though less so for intestinal schistosomiasis due to the fact that the prevalence of intestinal schistosomiasis remains closer to the school-age level and the early adulthood compared to that of urogenital schistosomiasis (Chandiwana et al., 1988; Traoré et al., 1998; Guyatt et al., 1999; Kabatereine et al., 2004). Lai et al. (2015) made predictions regarding population-adjusted prevalence and the number of school-aged children infected with Schistosoma spp in 2012 for all countries in SSA. For Zimbabwe, they estimated an overall prevalence of $25.2 \%$ for $S$. haematobium corresponding to 960.000 school-aged children, compared to our overall estimated population adjusted prevalence of $17.3 \%(2,129,309,000$ people - all ages). For $S$. mansoni, they estimated an overall prevalence of
$7.6 \%$, corresponding to 290.000 school-aged children in 2012, compared to our estimates of $5.1 \%$ overall prevalence $(622,549$ people - all ages). Furthermore, the earliest available population data of a satisfactory quality and resolution are from 1990. Appling the 1981 prevalence predictions with the knowledge that the Zimbabwe population grew from 7.2 to 10.5 million, from 1981 to 1990 , the number of predicted infections for 1981 appears overestimated. This would result in an even more pronounced decline in prevalence than what was found in the current analysis.

Finally, the two surveys include the infections acquired in the corresponding year because they were both conducted in the period September-December allowing enough time for the parasite to infect, mature and excrete eggs after the period when transmission is highest in the post-rainy season. Because the surveys also registered the infections acquired in previous years, climate data for these years could, with benefit, have been included but a paucity of climate data from the period leading up to the early survey prevented this. Furthermore, rainfall was the only predictor available for both 1981 and 2010, whereas the NDVI was only obtainable from late 1981 and an average of 1982-1984 (March through May) was used. Additionally, both prevalence and climate data were obtained at two specific points in time and do not in its real sense represent the development of prevalence or climate over the 30-year period. No information on tluctuations in prevalence during the 29 year period is available, but some information on climate is available in the form of yearly country averages (see suppl. II), which indicate that both temperature and precipitation are representative for the period, i.e. the years 1981 and 2010 were neither particularly cold/warm nor wet/dry years.

\section{Conclusions}

This study presents the first up-to-date Bayesian risk maps for $S$. haematobium and $S$. mansoni infection in Zimbabwe. To the best of our knowledge, this is the first study investigating the his-
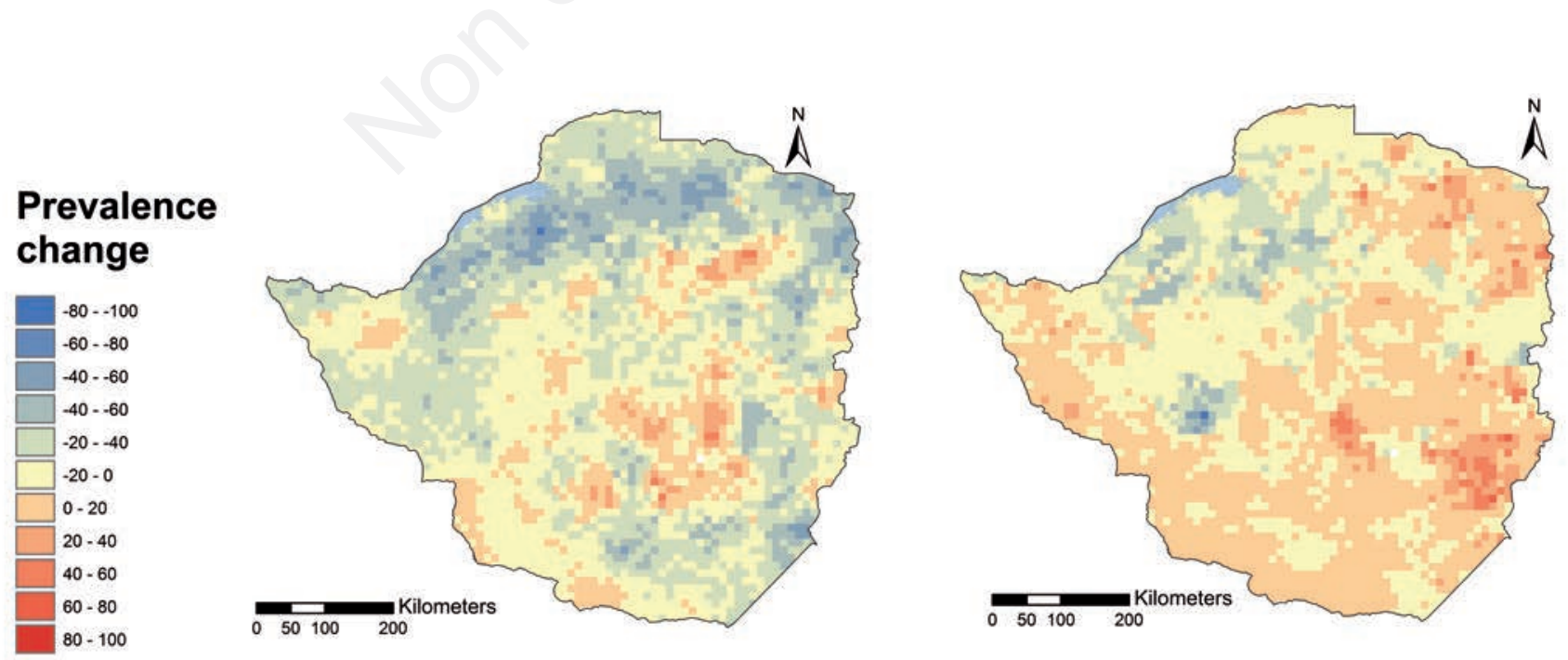

A

B

Figure 3. Change of predicted prevalence of urogenital (A) and intestinal (B) schistosomiasis from 1981 to 2010 (in percentage-points). 
torical change of schistosomiasis distribution and prevalence in relation to changes in climate using prevalence and climate data matching in time spanning a period as long as three decades. With the implementation of real-time climate data for the two periods, the results add to our knowledge about the impact of climate change on schistosomiasis and highlight the importance of a historical perspective when studying the impact of climate change on vector-borne diseases in general. Although a statistically significant relationship between climatic changes and the change in prevalence could not be established, the observed downward trend in schistosomiasis prevalence in Zimbabwe over the last three decades parallels a shift towards a drier and warmer climate.

\section{References}

Assare RK, Lai YS, Yapi A, Tian-Bi YN, Ouattara M, Yao PK, Knopp S, Vounatsou P, Utzinger J, N'Goran EK, 2015. The spatial distribution of Schistosoma mansoni infection in four regions of western Cote d'Ivoire. Geospat Health 10:69-79.

Batjes NH, 2012. ISRIC-WISE derived soil properties on a 5 by 5 arc-minutes global grid (ver. 1.2). Report 2012/01. WISE, Wageningen, Germany. Available from: http://library.wur.nl/ WebQuery/wurpubs/fulltext/206736

Center for International Earth Science Information Network, 2011. Global Rural-Urban Mapping Project, Version 1 (GRUMPv1): population density grid. NASA Socioeconomic Data and Applications Center (SEDAC), Palisades, NY, USA.

Chammartin F, Scholte R, Malone J, Bavia M, Nieto P, Utzinger J, Vounatsou P, 2013. Modelling the geographical distribution of soil-transmitted helminth infections in Bolivia. Parasite Vectors 6:152.

Chandiwana SK, Taylor P, Clarke VD, 1988. Prevalence and intensity of schistosomiasis in two rural areas in Zimbabwe and their relationship to village location and snail infection rates. Ann Trop Med Parasitol 82:163-73.

Cheesbrough M, 2006. District laboratory practice in tropical countries. Cambridge University Press, Cambridge, UK.

Chitsulo L, Engels D, Montresor A, Savioli L, 2000. The global status of schistosomiasis and its control. Acta Trop 77:41-51.

Clements ACA, Firth S, Dembele R, Garba A, Toure S, Sacko M, Landoure A, Bosque-Oliva E, Barnett AG, Brooker S, Fenwick A, 2009. Use of Bayesian geostatistical prediction to estimate local variations in Schistosoma haematobium infection in western Africa. B World Health Organ 87:921-9.

Clements ACA, Lwambo NJS, Blair L, Nyandindi U, Kaatano G, Kinung'hi S, Webster JP, Fenwick A, Brooker S, 2006. Bayesian spatial analysis and disease mapping: tools to enhance planning and implementation of a schistosomiasis control programme in Tanzania. Trop Med Int Health 11:490503.

Dellaportas P, Forster JJ, Ntzoufras I, 2000. Bayesian variable selection using the Gibbs sampler. Biostatistics-Basel 5:27386.

Edward GI, McCulloch RE, 1993. Variable selection via Gibbs sampling. J Am Stat Assoc 88:881-9.

El-Khoby T, Galal N, Fenwick A, Barakat R, El-Hawey A, Nooman Z, Habib M, Abdel-Wahab F, Gabr NS, Hammam HM, 2000. The epidemiology of schistosomiasis in Egypt: summary findings in nine governorates. Am J Trop Med Hyg 62:88-99.
Fulford A, Webster M, Ouma J, Kimani G, Dunne D, 1998. Puberty and age-related changes in susceptibility to schistosome infection. Parasitol Today 14:23-6.

Fürst T, Keiser J, Utzinger J, 2012. Global burden of human foodborne trematodiasis: a systematic review and meta-analysis. Lancet Infect Dis 12:210-21.

Guyatt HL, Brooker S, Donnelly CA, 1999. Can prevalence of infection in school-aged children be used as an index for assessing community prevalence? Parasitology 118:257-68.

Hairston NG, 1965. An analysis of age-prevalence data by catalytic models. B World Health Organ 33:163-75.

Hijmans RJ, Cameron SE, Parra JL, Jones PG, Jarvis A, 2005. Very high resolution interpolated climate surfaces for global land areas. Int J Climatol 25:1965-78.

Jarvis A, Reuter H, Nelson A, Guevara E, 2008. Hole-filled SRTM for the globe, version 4. CGIAR-CSI SRTM 90m database. International Center for Tropical Agriculture, Cali, Columbia. Available from: http://srtm.csi.cgiar.org

Kabatereine NB, Brooker S, Tukahebwa EM, Kazibwe F, Onapa AW, 2004. Epidemiology and geography of Schistosoma mansoni in Uganda: implications for planning control. Trop Med Int Health 9:372-80.

Katz N, Chaves A, Pellegrino J, 1972. A simple device for quantitative stool thick-smear technique in Schistosomiasis mansoni. Rev Inst Med Trop Sao Paulo 14:397-400.

Lai Y-S, Biedermann P, Ekpo UF, Garba A, Mathieu E, Midzi N, Mwinzi P, N'Goran EK, Raso G, Assaré RK, 2015. Spatial distribution of schistosomiasis and treatment needs in subSaharan Africa: a systematic review and geostatistical analysis. Lancet Infect Dis 15:927-40.

Lehner B, Verdin K, Jarvis A, 2006. HydroSHEDS technical documentation. World Wildlife Fund, Washington, DC, USA. Available from: https://hydrosheds.cr.usgs.gov/Hydro SHEDS_TechDoc_v10.doc

Lunn D, Thomas A, Best N, Spiegelhalter D, 2000. WinBUGS - a Bayesian modelling framework: concepts, structure, and extensibility. Stat Comput 10:325-37.

Lwambo NJS, Siza JE, Brooker S, Bundy DAP, Guyatt H, 1999. Patterns of concurrent hookworm infection and schistosomiasis in schoolchildren in Tanzania. T Roy Soc Trop Med Hyg 93:497-502.

Malone JB, Yilma JM, McCarroll JC, Erko B, Mukaratirwa S, Zhou X, 2001. Satellite climatology and the environmental risk of Schistosoma mansoni in Ethiopia and east Africa. Acta Trop 79:59-72.

Martens WM, Jetten T, Focks D, 1997. Sensitivity of malaria, schistosomiasis and dengue to global warming. Clim Change 35:145-56.

McCreesh N, Booth M, 2013. Challenges in predicting the effects of climate change on Schistosoma mansoni and Schistosoma haematobium transmission potential. Trends Parasitol 29:54855.

McCreesh N, Nikulin G, Booth M, 2015. Predicting the effects of climate change on Schistosoma mansoni transmission in eastern Africa. Parasite Vectors 8:1-9.

Midzi N, Mduluza T, Chimbari MJ, Tshuma C, Charimari L, Mhlanga G, Manangazira P, Munyati SM, Phiri I, Mutambu SL, Midzi SS, Ncube A, Muranzi LP, Rusakaniko S, Mutapi F, 2014. Distribution of schistosomiasis and soil transmitted helminthiasis in Zimbabwe: towards a national plan of action for control and elimination. PLoS Negl Trop Dis 8:e3014. 
Midzi N, Mtapuri-Zinyowera S, Mapingure MP, Paul NH, Sangweme D, Hlerema G, Mutsaka MJ, Tongogara F, Makware G, Chadukura V, Brouwer KC, Mutapi F, Kumar N, Mduluza T, 2011. Knowledge attitudes and practices of grade three primary schoolchildren in relation to schistosomiasis, soil transmitted helminthiasis and malaria in Zimbabwe. BMC Infect Dis 11:169.

Moodley I, Kleinschmidt I, Sharp B, Craig M, Appleton C, 2003. Temperature-suitability maps for schistosomiasis in South Africa. Ann Trop Med Parasitol 97:617-27.

Mukaratirwa S, Kristensen TK, 1995. A review on status of vector snails of urinary schistosomiasis in Zimbabwe. In: H.T.K. Madsen (ed.) A status of research on medical malariology in relation to schistosomiasis in Africa, Harare, Zimbabwe. Danish Bilharziasis Laboratory, Charlottenlund, Denmark, pp. 197-204.

Novella NS, Thiaw WM, 2012. African rainfall climatology version 2 for famine early warning systems. J Appl Meteorol Climatol 52:588-606.

Pedersen UB, Midzi N, Mduluza T, Soko W, Stensgaard A-S, Vennervald BJ, Mukaratirwa S, Kristensen TK, 2014a. Modelling spatial distribution of snails transmitting parasitic worms with importance to human and animal health and analysis of distributional changes in relation to climate. Geospat Health 8:335-45.

Pedersen UB, Stendel M, Midzi N, Mduluza T, Soko W, Stensgaard A-S, Vennervald BJ, Mukaratirwa S, Kristensen TK, 2014b. Modelling climate change impact on the spatial distribution of fresh water snails hosting trematodes in Zimbabwe. Parasite Vectors 7:1-12.

Pinzon JE, Tucker CJ, 2014. A non-stationary 1981-2012 AVHRR NDVI3g time series. Remote Sens 6:6929-6960.

R Core Team, 2013. R: a language and environment for statistical computing. R Foundation for Statistical Computing, Vienna, Austria.

Raso G, Matthys B, N'goran EK, Tanner M, Vounatsou P, Utzinger J, 2005. Spatial risk prediction and mapping of Schistosoma mansoni infections among schoolchildren living in western Cote d'Ivoire. Parasitology 131:97-108.

Raso G, Vounatsou P, McManus DP, Utzinger J, 2007. Bayesian risk maps for Schistosoma mansoni and hookworm monoinfections in a setting where both parasites co-exist. Geospat Health 2:85-96.

Schur N, Hürlimann E, Garba A, Traoré MS, Ndir O, Ratard RC, Tchuem Tchuenté L-A, Kristensen TK, Utzinger J, Vounatsou P, 2011. Geostatistical model-based estimates of schistosomiasis prevalence among individuals aged $\leq 20$ years in West Africa. PLoS Negl Trop Dis 5:e1194.

Schur N, Hürlimann E, Stensgaard A-S, Chimfwembe K, Mushinge G, Simoonga C, Kabatereine NB, Kristensen TK, Utzinger J, Vounatsou P, 2013. Spatially explicit schistosoma infection risk in eastern Africa using Bayesian geostatistical modelling. Acta Trop 128:365-77.

Simoonga C, Utzinger J, Brooker S, Vounatsou P, Appleton CC, Stensgaard AS, Olsen A, Kristensen TK, 2009. Remote sensing, geographical information system and spatial analysis for schistosomiasis epidemiology and ecology in Africa. Parasitology 136:1683-93.

Stensgaard A-S, Booth M, Nikulin G, McCreesh N, 2016. Combining process-based and correlative models improves predictions of climate change effects on Schistosoma mansoni transmission in eastern Africa. Geospat Health 11:94-101.

Stensgaard A-S, Jørgensen A, Kabaterina NB, Rahbek C, Kristensen TK, 2006. Modelling freshwater snail habitat suitability and areas of potential snail-borne diesase transmission in Uganda. Geospat Health 1:93-104.

Stensgaard A-S, Utzinger J, Vounatsou P, Hürlimann E, Schur N, Saarnak CFL, Simoonga C, Mubita P, Kabatereine NB, Tchuem Tchuenté L-A, Rahbek C, Kristensen TK, 2013. Large-scale determinants of intestinal schistosomiasis and intermediate host snail distribution across Africa: does climate matter? Acta Trop 128:378-90.

Tatem AJ, Noor AM, von Hagen C, Di Gregorio A, Hay SI, 2007. High resolution population maps for low income nations: combining land cover and census in East Africa. PloS One 2:e1298.

Taylor P, Makura O, 1985. Prevalence and distribution of schistosomiasis in Zimbabwe. Ann Trop Med Parasitol 79:287-99.

Traoré M, Maude GH, Bradley DJ, 1998. Schistosomiasis haematobia in Mali: prevalence rate in school-age children as index of endemicity in the community. Trop Med Int Health 3:21421.

Tucker CJ, Pinzon JE, Brown ME, Slayback DA, Pak EW, Mahoney R, Vermote EF, El Saleous N, 2005. An extended AVHRR $8 \mathrm{~km}$ NDVI dataset compatible with MODIS and SPOT vegetation NDVI data. Int J Remote Sens 26:4485-98.

Wildlife Conservation Society and Center for International Earth Science Information Network, 2005. Last of the wild project, version 2, 2005 (LWP-2): global human footprint dataset (geographic). NASA Socioeconomic Data and Applications Center (SEDAC), Palisades, NY, USA.

Woodhall DM, Wiegand RE, Wellman M, Matey E, Abudho B, Karanja DM, Mwinzi PMN, Montgomery SP, Secor, WE, 2013. Use of geospatial modeling to predict Schistosoma mansoni prevalence in Nyanza Province, Kenya. PloS One 8:e71635

Yang GJ, Vounatsou P, Zhou XN, Tanner M, Utzinger J, 2005. A potential impact of climate change and water resource development on the transmission of Schistosoma japonicum in China. Parassitologia 47:127-34.

Zhou XN, Yang GJ, Yang K, Wang XH, Hong QB, Sun LP, Malone JB, Kristensen TK, Bergquist NR, Utzinger J, 2008. Potential impact of climate change on schistosomiasis transmission in China. Am J Trop Med Hyg 78:188-94. 